\title{
Disruptions in spatial networks: a comparative study of major shocks affecting ports and shipping patterns
}

Pre-final version of the article published in Networks and Spatial Economics, 20: 423-447 (2020)

\author{
Laure ROUSSET \\ Ecole Nationale Supérieure (ENS) \\ Département des Sciences Sociales \\ 65 Allée d'Italie, F-69007 Lyon, France \\ laure.rousset@ens-lyon.fr \\ Tel. $+0033(0) 437.376 .000$ \\ César DUCRUET ${ }^{1}$ \\ Centre National de la Recherche Scientifique (CNRS) \\ Délégation Régionale DR05 \\ 1 Place Aristide Briand, F-92195 Meudon, France \\ Email: cdu@parisgeo.cnrs.fr \\ Tel. $+0033(0) 145.075 .050$
}

\begin{abstract}
In this research, the effect of local exogenous shocks on seaports and maritime networks is assessed throughout three case-studies. The Hanshin-Awaji earthquake, the 9/11 World Trade Center attack and hurricane Katrina triggered a shock on Kobe, New York and New Orleans respectively and led to temporary port failures. A global database on vessel movements is computed to gauge the intensity, duration and scope of these shocks with descriptive statistics. Port-centered analyses of the disrupted ports and their geographic as well as topological neighbors are conducted to assess the resilience of local port systems using traffic volumes, distances, and graph-theoretical methods at various time scales, from daily to yearly evolutions. Main results demonstrate certain similarities between the three cases given the importance of traffic specialization and of the spatial range of disruption.
\end{abstract}

Keywords: Complex networks; Disruption; Graph theory; Kobe; Maritime transport; Natural disaster; New Orleans; New York; Port; Shipping network; Shock; Targeted attack

\section{Acknowledgements}

The authors thank Justin Berli for his support on maritime distance calculation. The research leading to these results has received funding from the European Research Council under the European Union's Seventh Framework Programme (FP/2007-2013) / ERC Grant Agreement n. [313847] "World Seastems".

\footnotetext{
${ }^{1}$ Corresponding author
} 


\title{
Disruptions in spatial networks: a comparative study of major shocks affecting ports and shipping patterns
}

\begin{abstract}
In this research, the effect of local exogenous shocks on seaports and maritime networks is assessed throughout three case-studies. The Hanshin-Awaji earthquake, the 9/11 World Trade Center attack and hurricane Katrina triggered a shock on Kobe, New York and New Orleans respectively and led to temporary port failures. A global database on vessel movements is computed to gauge the intensity, duration and scope of these shocks with descriptive statistics. Port-centered analyses of the disrupted ports and their geographic as well as topological neighbors are conducted to assess the resilience of local port systems using traffic volumes, distances, and graph-theoretical methods at various time scales, from daily to yearly evolutions. Main results demonstrate certain similarities between the three cases given the importance of traffic specialization and of the spatial range of disruption.
\end{abstract}

Keywords: Complex networks; Disruption; Graph theory; Kobe; Maritime transport; Natural disaster; New Orleans; New York; Port; Shipping network; Shock; Targeted attack

\section{Introduction}

As $90 \%$ of trade is carried by sea, maritime transport is the backbone of international exchanges. This major industry constitutes the maritime leg of supply chains which are organized on a global scale, linking various markets and companies (Pettit and Beresford, 2018). The supply chain relies on shippers and carriers who transport all sorts of commodities from one place to another via specialized or cargo ships, from grains to oil, cars to meat. The global maritime network is thus composed of the sum of agents (e.g.port operators, shippers, and carriers) that interact to form a large global market (Rodrigue et al., 2013).

Container shipping, in particular, underwent tremendous changes in recent decades as a handful of major shipping companies came to dominate this sector by servicing a global coverage of their clients through a limited number of ports (see Frémont, 2015 for the case of the CMA-CGM). The constant evolution of this system is reflected in the changing port selection factors of shipping lines, from shipping costs, proximity of markets, to transshipment activities allowing continental supply chains to connect with each other through intermediate nodes (Rodrigue and Notteboom, 2010). The lowering trade and transportation costs, for several decades, is one important factor in such an evolution, but also the fact that container shipping is an oligopolistic market (Lee et al., 2012), as horizontal integration between carriers developed increasingly since the 2008 global financial crisis (Frémont, 2015). One consequence on ports is a highly hierarchized structure, with larger hub and gateway ports linking smaller ones through feeder services, since the sector's liberalization in the mid-1990s (De Monie et al., 2011). Bulk markets function differently - although many commodities are increasingly containerized, focusing on raw materials purchased on-demand and bound to specific locations for export such as coal and grain.

Maritime transport differs from other transport modes as it does not rely on track infrastructure such as railways or roads. Routes and nodes are thus more flexible than terrestrial transportation, although they remain influenced by political (trade regulations, embargoes, piracy), geographic 
(climatic conditions, tidal ranges), and technical factors (port accessibility and costs). These factors can trigger risks of failure for shipping lines and ports, as companies rely on highly specialized fleets and terminals to operate, being more exposed than other modes to certain hazards such as storms, earthquakes and hurricanes causing delays, wreckage, or port infrastructure collapse (Cao and Lam, 2018). Insurance companies support the financial risks of such a trade, especially since the value of the commodities usually exceeds transportation costs. If the quantitative assessment of disruption impacts on port and shipping operations is a relatively dynamic research area in the academic literature, it often remains focused on the port itself without considering the rest of the network (Hall, 2004).

The present study considers the maritime network and its nodes as a whole, without observing and evaluating the diversity of agents and their decisions, bearing in mind the risk of any ecosystemic approach (Marston et al., 2005). How can different disruptions occurring in different places be compared? Various directions shall be used to answer this core question: (1) the degree to which differences in magnitude, context, geography, timing, and nature of the shock do not erase the possibility to find similarities in traffic and connectivity evolution; (2) the fact that the specialization of nodes, carrying different proportions of traffic types (e.g. container, bulk, passenger, general cargo), implies different means of cargo handling and transport and therefore different sensitivity to disruption, cargo diversity going along robustness; and (3) the possibility for rerouting options and inter-port cargo transfers to exhibit similar mechanisms within a given regional port range or system, depending on geographic / topological proximity or other factors.

One main statement is that disruptions provoke sudden changes in traffic and connectivity levels due to the damage caused on port and urban infrastructures such as roads (Chang, 2000) and railways (Rodrigue, 2004), berths and quays, especially for natural disasters. From this situation a partial or complete port failure would result, i.e. the inability for a port to operate as usual. To test this idea, three major gateway ports situated in two of the world's richest countries were selected: Kobe, New York, and New Orleans, as most important ports are also the most critical (Lhomme, 2015). Disruptions occurred in the same decade (1995-2005), coinciding with liberalization trends, the declining influence of distance on trade, and the rise of global supply chains. Yet, three events of different nature were chosen. The Hanshin-Awaji earthquake (17 January 1995) demolished $90 \%$ of Kobe port, $6^{\text {th }}$ largest Japanese port in terms of throughput in 1994, as well as several major roads and railroads. The World Trade Center (11 September 2001) terrorist attack did not physically harm New York port, the largest U.S. Atlantic port, but the latter closed for security reasons during one week and the New York and New Jersey Port Authority lost 74 employees as their head office located in the Twin towers could not operate as usual (Rodrigue, 2004). Hurricane Katrina (29 August 2005) caused the flooding of New Orleans port city, $2^{\text {nd }}$ largest U.S. Gulf coast port, and the emergency evacuation of the population. Operating the ports of New Orleans and South Louisiana was thus made difficult because of labor shortage, although it was a crucial period for the export of grains and cereals. All three events, although they differ in their nature, intensity and scope, triggered a shock in maritime traffic and disrupted the usual operation of these ports: they are thus exogenous to maritime activities but impacted them.

Some works provide a precise documentation for each shock, namely Kobe (Edgington, 2011; Okuyama, 2015; Oliva and Lazzeretti; 2017), New York (Chernick, 2005; Gotham and Greenberg, 2014; Sorkin and Zukin, 2002), and New Orleans (Dolfman and Fortier, 2007; Kates et al., 2006; Leavitt and Kiefer, 2006; Vigdor, 2008; Wachtendorf et al., 2013). This is complemented by reports from local authorities or ministries, in both Japan (City of Kobe, 2014; Kunishima and Abe, n.d.), and the USA (Amdal and Swigart, 2010; Bamberger and Kumins, n.d.; Cieslak, 2005; Frittelli, n.d.; 
Grenzeback et al., 2008; Irwin, 2005; Reuters, 2005). However, these shocks have not been compared with each other yet, especially from a quantitative and network perspective. Scholarly studies looked at law and economic issues such as the implementation of antiterrorism policies for general freight in the case of New York (Bradbury, 2010; MacPherson et al., 2006; Rose et al., 2010) and in wider maritime-related terrorism studies (Michels et al., 2013; Richardson, 2004), and the geographical and urban dimensions of terrorism (Cowen and Bunce, 2006; Cutter et al., 2014). These works provide a lot of precise information on each disruption that enrich our comparative perspective.

The remainders of this article are organized as follows. Section 2 reviews the literature analyzing maritime network vulnerability and robustness to exogenous shocks. Section 3 introduces the case studies and justifies the proposed methodology for understanding maritime network dynamics before, during, and after those shocks. Section 4 assesses the effect of shocks on ports using descriptive statistics, before concluding in Section 5 about the lessons learned for both research and practice.

\section{Research background and objectives}

International shipping has become a highly competitive industry in the last decades through diffusion and innovation waves (Guerrero and Rodrigue, 2014) as well as horizontal and vertical integration (Robinson, 2002; Song et al., 2005). Between local and international contexts, the concepts of glocalization (Lee and Ducruet, 2009) and co-opetition (Asadabadi and Miller-Hooks, 2018) are potentially useful to understand the specific vulnerability of ports and their linkages. There is a contradiction between the need for ports to be interconnected and the necessity to secure their throughput (and related profits) from disruptive events. At the same time, the increasing power of global transport actors (of which shipping lines) reinforces port competition (Slack, 1993) through network rationalization. Past disturbances are important due to the "memory effect" of supply chain actors in their port selection (Lemarchand and Joly, 2009). If supply chain actors have their own impact from - and response to - shocks, political conditions always play a role (Vigarié, 1995). The capability to recover from disruptions in a shipping context is defined by Rodrigue et al. (2013) as the possibility to restore past activity within a certain time lapse, over which the transport system loses its resilience. Berle et al. (2011) defined transport system vulnerability as the weakening ability to endure disruptive events both internally and externally.

Yet, the existing literature on port-related shocks long remained monographic or theoretical. Scholars studied infrastructure and throughput impacts from diverse angles, such as war impact (Walker, 1989), economic crisis impact (De Monie et al., 20011), natural disaster impact (Chang, 2000, 2003; Chang and Nojima, 2001; Xu and Itoh, 2017; Godoy Luis, 2007; Grenzeback et al., 2008), and political change impact (Wang and Ducruet, 2013). Quantifying the costs of such events, as Rose and Wei (2013) do for port shut-downs, is crucial, especially for insurance companies. In the field of risk analysis, Rosoff and von Winterfeldt (2007) studied possible terrorist attacks on Los Angeles and Long Beach ports to estimate shut down duration and related costs (e.g. evacuation, property value, and decontamination). Economists such as Paul and Maloni (2010) modeled dynamic ship rerouting in the case of labor strike or natural disaster for U.S. West coast ports to minimize congestion and economic losses. Focusing on the same area, the geographer Peter Hall (2004) provided a critical view on port economic impacts as they fail to address substitution possibilities, assuming that cargo throughput and economic measures share a continuous, monotonic relationship. Other related literatures usually adopt an agent-centered approach, which requires deep knowledge of how actors 
(e.g. port authorities, shippers, etc.) take their decisions. This constrains comparisons of several shocks occurring in different historical and geographical contexts. The relational, or network approach is thus a possible way to elucidate the comparability of shocks (Viljoen and Joubert, 2016) because the maritime network and its response result from decisions of many autonomous agents, although knowledge about how such decisions are made remains limited, especially in terms of "rewiring". This calls for a both empirical and network approach when studying the impact of exogenous shocks on seaports.

Existing studies of shocks in networks are numerous, using various concepts such as network robustness, vulnerability, and resilience (see Li and Ozbey, 2015; Caschili et al., 2015; Kireyev and Leonidov, 2018). These concepts enable to assess node and network reaction in the face of unpredicted events which lead to node or link failures, and their ability to recover from such shocks. Robustness, defined by Dekker and Colbert (2004) for any network as "the continued ability of the network to perform its function in the face of attack", is thus addressed by physicists who aim to draw general conclusions such as "robust networks will continue functioning in spite of such damage and outages (up to some level of damage)" (Callaway et al., 2000), or who distinguish static robustness from dynamic robustness (Dou et al., 2010). As stated by Viljoen and Joubert (2016), the study of complex network vulnerability faces "various targeted disruption strategies aimed at either removing nodes or links, although node removal is far more prevalent". In addition to wider approaches (Hayashi and Matsukubo, 2006; Scott et al., 2006; Cook et al., 2014), this field also studies particular communication networks such as power grids (Wang and Rong, 2011), urban transit systems (Daganzo, 2010; Derrible and Kennedy, 2010), roads and railways (Ducruet and Beauguitte, 2014), congested roads (Nagurney and Qiang, 2007), and air transport (Lordan et al., 2016).

Maritime networks have been somewhat left aside in comparison with other transport modes and networks, which is counterintuitive, given their strong economic importance (Bernhofen et al., 2016). This is perhaps because maritime networks are often seen as only one part of a larger supply chain (Banomyong, 2005; Chen and Miller-Hooks, 2012; Loh and Van Thai, 2014; Wu et al., 2007). According to Earnest et al. (2012), robust maritime systems are those where "throughput does not decline appreciably when a port is disabled", i.e. 28 days after an attack. Attacks of all kinds are often seen as long-term disruptions of one or several nodes; they differ from delays and minor interruptions that are part of the everyday normal operating risks of a supply chain (Dillon and Mazzola, 2010). Such interruptions can be seen as four stages of disruption: ranging from delay, deviation, stoppages, to the complete loss of the service platform (Gurning et al., 2013). Operations research thus provided the largest amount of works including also more conceptual approaches about maritime network vulnerability (Loh and Van Thai, 2014; Thai, 2009). In this field, empirical approaches using a network-based approach mainly deployed simulation models to measure how unpredicted shocks threaten network efficiency (see Asadabadi and Miller-Hooks, 2018; Burden et al., 2016; Mullai and Paulsson, 2011; Omer et al., 2012; Shafieezadeh and Ivey Burden, 2014). In addition, some authors studied port resilience in the face of disruptions and liner shipping coping with such events (Shaw et al., 2017; Achurra-Gonzalez et al., 2017; Qi, 2015).

Maritime studies have increasingly integrated a network approach, while network studies did the same for maritime transport. While applying graph theory to maritime data was first developed by geography in the 1960s (see Robinson, 1968), it is only in the in the late 2000s and early 2010s that complex networks methods were considered in a maritime context. Chinese physicists analyzed global shipping networks (Hu and Zhu, 2009; Deng et al., 2009) considering the underlying network as a non-planar graph and using schedule data obtained from companies. Authors mainly compare 
maritime network topology to wider scale-free and small-world configurations, without ignoring the need for a more holistic approach when it comes to economic and operational factors such as cargo destination, weather, oceanic currents, politics, etc. The complex network nature of container shipping was confirmed by Viljoen and Joubert (2016), as a few super nodes have a high level of interconnectivity compared with the rest, making individual nodes (and the whole system) extremely vulnerable to targeted disturbances.

Furthermore, the availability of new data sources such as Lloyd's List (Arvis et al., 2019) and radar or satellite (Automated Identification System, AVHRR) triggered new perspectives, enabling to study real flows (Høye et al., 2008). The study of shocks in maritime networks thus started with the analysis of network properties, later followed by more specific approaches in terms of vulnerability, mainly giving birth to empirical, descriptive statistical case studies. On a world scale, Lhomme (2015) established that maritime networks were less vulnerable than the British electrical network due to the lack of route infrastructure but at the same time more vulnerable due to the presence of hubs as in scale-free networks (for a general discussion, see Barthelemy, 2015). Short periods of time often remained under-studied as pioneering analyses of maritime networks neglected time-related information within the data according to Guinand and Pigné (2015) in their analysis of 365 days of containership worldwide movements using shifting time windows. Node failure is thus more studied than link failure, although it was established (O'Kelly, 2015) that hub network vulnerability lays not only in the hub nodes but also in the links, which constitute the backbone of the network. Applied mathematics and especially clustering methods (stochastic block model) allowed analyzing the impact of USSR collapse on the Soviet maritime ego-network (Zreik et al., 2017), while simpler descriptive statistics served a better understanding of strategic (e.g. interoceanic canals) and political factors (e.g. embargo, regime collapse) on maritime network patterns (Fang et al., 2018).

This literature review shows that despite increasing research on shocks on ports and maritime networks, there remains a need to provide an empirical comparison of real-world disruptions under different contexts. In other words, are there similarities in the way different disruptions affect different ports? May those similarities and differences be better explained by topology, geography, or other dimensions? Our analysis of the cases of Kobe, New York, and New Orleans is a first step in such a direction, notwithstanding the definition of a rigorous methodology in the next section.

\section{Data and methodology}

We constructed a temporal and worldwide graph where nodes are ports and links (edges) are vessel movements or port-to-port voyages, using actual vessel movement data provided by Lloyd's List Intelligence, a major insurance company which insures about $80 \%$ of the world fleet. This database links three main tables: places (mostly ports, but canals and other locations as well) and their coordinates, vessels (cargo carrying capacity), and most importantly movements (arrival and departure dates). Data was extracted for each case in a similar manner, also depending on its availability. Each node and link could be weighted, depending on the time window, by the sum of vessel capacities in deadweight tonnage (DWT) or twenty-foot equivalent units for containers (TEU).

The delineation of time and space granularity needed careful attention. First, disruptions may be analyzed according to varying spatial scales, from the affected node itself (epicenter) to a wider area including its close or faraway neighbors. Here it is important to establish a link with numerous models and quantitative analyses of so-called port systems that despite various evidences and interpretations provide a useful methodological framework (Notteboom et al., 2009). This port 
system may be defined administratively and politically (boundaries), geographically (given radius or range), or topographically (connected neighbors), providing floor for the application of various analytical tools like traffic concentration and network connectivity indices. Our literature review demonstrated that much previous works having focused on one single port, this article shall compare not three different ports but also for each one, the evolution of its neighbors within a certain scale or port system. Regions derive from Lloyd's List delineation: U.S. Atlantic Coast and Canadian East Coast (New York), U.S. Gulf Coast and Caribbean (New Orleans), Japan and Northeast Asia (Kobe). Distances between ports were computed between ports using a virtual maritime grid with nautical knots as the metric (see Berli et al., 2018 for a deeper methodological specification).

Second, the time-scale also varies from the day of the disruption itself and the days before and after, under a certain threshold, under which the aforementioned indices may be calculated (e.g. on a weekly, monthly, or yearly basis). The daily view is useful to identify specific shipments as in the case of North Korea where data is scarce (Ducruet et al., 2017) but it is perhaps too disaggregated to witness middle or long-term recovery processes. We thus compare not only shocks and places but also temporality made of both structural and conjectural evolutions and fluctuations (Guinand and Pigné, 2015). However, the yearly figure is based on a fixed time period, the same for all ports, aggregating all vessel movements and terminal operations. Practically, port system evolutionary models insisted on the ideal-typical phasing of traffic concentration and de-concentration in time and space, mainly due to congestion and lack of space (Hayuth, 1981; Slack and Wang, 2002) fostering the rise of peripheral ports at the expense of major port gateways or load centers. Yet the hub dependence model (Ducruet, 2008) is particularly useful to our approach since it focuses on the impact of an economic crisis on a maritime network node. As the crisis deepens, more traffic is rerouted via a neighboring transit (or transshipment) node to maintain the accessibility of the affected economy to global shipping and trade. Our empirical analysis shall take into account those models' frameworks.

The time delineation was chosen as follows. We documented the Kobe earthquake using 1993-1996 data to best distinguish normal from disrupted activity; same for New York (2000-2002) and New Orleans (2004-2006). Some comparability issues emerged, however, given the unavailability of certain months, the occurrence of some failures at the beginning or the end of a given month making it difficult to trace back or forward the shock, as mentioned above in the case of traffic conjectural or cyclical fluctuations. For Kobe, missing data for February 1995 made it impossible to measure the continuation of the shock, so one may wonder whether two weeks suffice to understand Kobe's recovery. The nature of affected nodes should not be ignored, as in the case of New Orleans. Affected by $29^{\text {th }}$ August 2005, New Orleans had been one of other ports like Houston to be affected by this record-breaking Atlantic hurricane season (cf. the Rita hurricane hitting Houston by September 25), making the comparison with other summers possible but difficult, and the comparison with winter seasons irrelevant, since exporting grain is a seasonal activity following summer harvest.

The topological setting was also questioned. We built the graph using both space-P and space- $L$ topologies (see Hu and Zhu, 2009). Contrary to the space-L topology connecting only directly adjacent ports along vessel voyages, space- $L$ better reflects trade patterns (larger nodes are gateways) over shipping patterns (larger nodes are hubs), which is more relevant in our study, although gateway and hub functions cannot be distinguished from each other in this data. Such a global matrix allowed measuring individual port centrality and regional network structure, while centrality indicators have the potential to palliate the mentioned lack of information on the true nature of vessel movements. We extracted the ego-networks at two geographic scales: a) regional 
(using space-L), i.e. all the links connecting the belonged region's ports with each other, with their neighbors, and between those neighbors; b) local (using space-P), i.e. all the links connecting Kobe, New Orleans, and New York, to their topologically adjacent ports and among the latter ports (see Zreik et al., 2017). Ego-networks better fit the study of shocks compared with more regional networks defined based on arbitrary geographic limits because the latter have no specific mathematical definition (Mareï and Ducruet, 2015) and places the affected port node at the center of the analysis, notwithstanding the inclusion of links bypassing - or indirectly connected to - this node. From the aforementioned matrices was also extracted the minimum spanning tree (i.e. Kruskal algorithm) before and after each disruption, namely the single route connecting all ports and catching the maximum traffic volume. In such a route, ports are compared based on their betweenness centrality (number of occurrences on shortest paths) and their Strahler index (ramification level).

Last but not least, we also questioned the definition of cargo types. From such a perspective, we may expect that certain traffic types are more robust than others to shocks. Container flows in particular (Xu and Itoh, 2017) are more likely to be footloose in the advent of a shock than bulk because of a higher sea-sea transshipment share across port terminals (cf. hub and spokes, interlining services). In addition, container flows may use diversion to palliate shocks by using transshipment and/or intermodal services at another port. Bulks are more place-dependent (cf. hinterlands, factories, markets, resources) and infrastructure-dependent (specialized cranes and terminals) so that the affected port is more difficult to be bypassed by maritime flows, especially if the needed infrastructure is still available. General ships seem to be ordinary in the 1990s, but have increasingly been replaced by specialized fleets since then, as they transported mixed shipments. The specialization perspective also allows us to better detect how traffic losses for certain trades may have been compensated by gains in other trades. This particularly truer for specialized ports, while more diversified ports tend to be larger - and therefore more robust to shocks. Lloyd's List classifies vessels into 13 general types and 159 sub-types, corresponding to commodity categories (e.g. oil, gas, cement) or specific transport means (e.g. passengers, vehicles, containers), which we aggregated into five main categories ${ }^{2}$.

\section{The comparison of disruptions in Kobe, New York, and New Orleans}

\subsection{Overall traffic evolution}

To verify these hypotheses, we first provide a yearly view (Figure 1) before diving in a daily view (Figure 2) of the evolution of selected nodes' strength (or total traffic over all edges) since the 1970s. Figure 1 shows that Kobe is rather specific by a) its close resemblance between total vessel traffic ( 4 months per year) and container throughput (whole year round); and b) a huge activity drop in 1995. In comparison, New York shows a moderate drop in 2001 for total vessel traffic (dotted line) followed by a more acute one in 2002, but container throughput continues to grow. The case of New Orleans shows a huge drop in 2004 for total vessel traffic (dotted line), while container throughput, rather low in tonnage compared with the two other ports, remains relatively stable. We can learn from such a picture that our selected ports reacted in very diverse ways to disruptions, certainly due to the duration and magnitude of the shocks but also to the specialization and location, port system configuration of these ports.

\footnotetext{
${ }^{2}$ Certain vessel types were excluded, especially those not related with cargo operations, such as research ships, dredgers, tugs, etc. which undertake maintenance, safety, and other purposes
} 
[Figure 1]

Vessel traffic per day was calculated before and after the shocks for each studied port (Figure 2). At first sight, an immediate fall of the throughput is observed. A week before the event, Kobe's daily throughput was 800000 DWT: this figure dropped to 200,000 DWT on January 19. A comparable shock is observed in New York, which sees 200,000 DWT arriving on the September 12, the day after 9/11, despite a traffic just below one million DWT a week prior to the event. New Orleans' traffic is much more irregular, although there is a clear drop in traffic levels in terms of DWT after the August 29. This is probably due to the fact that the hurricane was, unlike for both other shocks, predicted by weather forecasts which allowed to take security measures before the occurrence of the event. The impact of Katrina may thus have started before the hurricane hit New Orleans. Ports operating in this area are used to such events during the hurricane season, as for instance Houston suffered from another hurricane by late September 2005, so that Katrina was not as unpredictable as for the Kobe and New York cases. Nonetheless the 2005 hurricane season set a record, and Katrina was a major disaster for New Orleans, hence making the three cases comparable. These exogenous shocks affecting traffics levels are due to the destruction of infrastructure for Kobe and marginally New Orleans, the implementation of emergency security measures in New York, and labor shortage in the aftermath of Katrina, as workers and inhabitants of New Orleans were evacuated.

[Figure 2]

From these figures can be concluded that the three traffic falls differ in their duration and temporality. Whereas it lasted a few days for the port of New York, it took much more time in New Orleans' and Kobe's cases. Both latter cases can be qualified of total temporary port failures with a duration of several weeks, or months, whereas New York's shock is a momentary port failure with a duration of only several days. These failures imply that these ports are unable to operate as usual and to act as gateways. Yet the traffic is not reduced to zero: some ships keep arriving and departing from the affected port, at least every few days. Despite major destructions or security concerns, some traffic remains able to be dealt with. This calls for traffic-differentiated analyses.

\subsection{Traffic specialization}

Based on five main traffic categories, we observe that for all three shocks (Figure 3), container traffic did not go back to previous levels during the year after the event. This is especially true in Kobe's case, which takes five months to get back to half of the traffic, after reaching the bottom line in March 1995 with 1,800 thousand DWT. One year after the earthquake and despite the full reopening of the port, container ships only accounted for 8,800 thousand DWT. New York faces quite a different pattern as between March 2000 and December 2002, the total container traffic is actually growing in DWT. The $9 / 11$ shock seems to happen in a larger trend of growth, which facilitates the recovery which is nonetheless chaotic and takes up to five months, although lack of data makes analyses risky.

Bulk and liquids trade did not react in the same way to the exogenous shocks: this traffic represents a marginal activity for Kobe, and variations are difficult to perceive on this scale. The shock seems to be less severe than for container and general cargo ships, although it also seems to vary according the time in the year. As it was reported that only 8 berths in a total of 186 were still operated right after the earthquake but for ships delivering emergency supplies, bulks and general cargo make no exception, in a context of massive (physical) destruction. Bulk ships represent the majority of New Orleans' traffic, and seem to flee the port in September before going back to previous levels in 
November. Tanker traffic seems to be highly variable depending on the month, particularly in New York and New Orleans. Tanker ships collapse during the Katrina shock, whereas this traffic represents about half of the ships calling at New York before the shock. In New York's case, the fall is not as severe as for containerships.

From these analyses can be concluded that container traffic tends to affected hit ports, making this network resilient to targeted attacks and container ports highly vulnerable in the face of such disruptions. These results confirm that the notion of discrete hinterlands is no longer valid for containerized traffic (Slack, 1993), and no single port is essential to container traffic. Other traffic such as liquid may still ensure the port to have its own hinterland as specialized infrastructure such as pipelines is needed. Furthermore, the individual robustness of a single port is very limited in the case of an exogenous shock. This may be due to the high competition there is amongst agents in this specific network. This affects the robustness of each maritime network. In this context, containerization is to be seen as a major progress in reducing the vulnerability of this network. This standardized mode of transportation simplifies logistics and is a competitive market. Maritime trade and traffic levels vary according specific logics depending on the types of ships and transported goods. Exogenous shocks affecting seaports thus differ in their intensity and duration for each considered traffic: robustness depends of all these factors.

[Figure 3]

\subsection{The diffusion of disruptions}

Because disruptions may have direct and indirect impacts on other nodes than the affected one, our analysis raises the question of the scope of disruptions. As explained by Lhomme (2015) in the context of (maritime) spatial networks, targeted attacks do not erase traffic but it reroutes it from the damaged node to neighboring nodes. The latter ports can thus grow and replace the damaged port due to systematic rerouting for long-term disruptions. In this cost-based network, shippers' demand remains the same, except if their own economic activity is disrupted. In the latter case, supply chain actors of which carriers have to find alternative options. Asadabadi and Miller-Hooks (2018) see disruption as a system where affected port and other ports are interdependent. However, while rerouted traffic may be a durable benefit or "window of opportunity" (Jacobs and Notteboom, 2011) to catch traffic on the short to long-run, it also can cause congestion in the destination port(s) that is already busy for its own operations. - as in the case of large disasters in Kobe and New Orleans.

\subsubsection{Spatial evolution}

To verify which ports may have been impacted by these shocks, the weekly traffics of several topographically close ports (on the same coast or country) were surveyed. The selected ports account for $90 \%$ of the previous to the shock traffic for each considered area: whole Japan, US Atlantic coast, and US Gulf coast. Distance from the failing port may be a factor to explain traffic variations of geographic neighbors. Small and close ports could act as emergency substitutes in case of port failure, which could explain higher absolute variations. These ports remain of small interest, as their role is short-lived and their sizes don't durably increase, hence the choice to consider only the largest ports making up $90 \%$ of the traffic. 
Figure 4 shows the absolute traffic variation of vessel traffic for each port system, including the affected port as it is an integral part of the system. There is a trend for faraway ports to suffer less from disruptions. On the 14-day scale, Kobe's determination coefficient is well significant $\left(R^{2}=\right.$ 0.5844 ), as strong variations are usually observed in the vicinity. The strongest drops are affecting ports located less than $750 \mathrm{~km}$ away, whereas most ports further than $1500 \mathrm{~km}$ away tend to see no variation or a growth in their throughput. A similar pattern is observed for the $9 / 11$ shock, despite a less significant correlation between distance and throughput variation $\left(R^{2}=0.4159\right)$. One difference is that ports in the vicinity of New York are not necessarily the most affected, such as Charleston (see also Figure 4 providing a cartography) and Great Lakes ports, while middle-range ports exhibited high growth rates but small volumes (e.g. Boston, Portland). Most of New York's topographic neighbors see an absolute increase in port throughput after the shock, which can indicate a (temporary) rerouting role.

These results are also in line with New Orleans' case, where there is a clear link between throughput variation and distance $\left(R^{2}=0.4691\right)$. This may be due to the fact for this shock that less ports are surveyed (only ports making up $90 \%$ of the throughput of American Gulf coast are taken into account), and that the maximum distance from New Orleans is $1200 \mathrm{~km}$. Again, ports seeing a fall in their throughput volume tend to be located less than $750 \mathrm{~km}$ away from New Orleans, whereas those seeing a growth are, for all except one, further than $800 \mathrm{~km}$ away from New Orleans, including non-US Caribbean ports.

[Figure 3]

[Figure 4]

\subsubsection{Network evolution}

We first analyzed subnetworks of the global maritime system by extracting the ego-network of each belonged region (space-L) (Figure 5). To ensure comparability, we circumscribed the temporal scale to a snapshot of vessel flows 14 days before and 14 days after each disruption, using both betweenness centrality and Strahler index to compare ports' situation in the obtained optimal route (cf. minimum spanning tree). Previous to the shock, Kobe and New York exhibit top centrality scores contrary to New Orleans, standing out as a secondary port compared with Houston, the major hub of the figure. While all three ports lost in centrality in their belonged network after the shock, this was felt mostly at Kobe and New York, as New Orleans kept its previous position as a secondary hub. Another important result is the changing situation of other ports than the affected one. While Houston keeps leading network centralization, it ceased to be the major hub after the shock, becoming just one among other hubs like Rio Haina (Dominican Republic), Point Lisas (Trinidad and Tobago), Puerto Cabello (Venezuela), Nassau, and Florida ports (Tampa, Port Everglades). Northeast Asia witnesses a leadership shift from Busan and Hong Kong to Taichung (Taiwan) and Newcastle (Australia), although the first two ports are still in a relatively central situation. Yet, the ports previously centered upon Kobe had lost centrality after disruption, implying an impact beyond Kobe itself but also on its connected neighbors. In the case of New York, centrality shifts also occurred with a clear geographic background, namely in the proximity (Leonardo in New Jersey, U.S. Atlantic coast ports) and across the Canadian border from Halifax to Great Lakes ports.

[Figure 5] 
Secondly, Table 1 provides an overview of the topological structure of the three ego networks (see Appendix 1 for the definition of network indices), in order to better focus on the subtle mix between local and global scales underlying nodes' situation (Liu et al., 2018). A striking result is the loss of numerous nodes in the immediate aftermath of the shock: between the previous week and the next one, Kobe lost $54 \%$ of its neighbors, New York $25 \%$ and New Orleans $41 \%$. On the second week after the shock however, results are contrasted: whereas New York got almost all its neighbors back, Kobe remained with the 31 neighbors left after the earthquake and New Orleans continued to lose neighbors, with only 17 remaining. All the ports seem to have gotten back to their previous number of neighbors at the end of two months after the shocks, although there are no indications here that the retrieved nodes are the same that were lost in the shock. Retrieved nodes can be smaller ports and blur the loss of crucial connections.

The fall is even stronger for the number of edges, which expresses the activity of the hit port as well. This is also true at the month level as the evolution is similar for all three shocks. Kobe's ego network lost $74 \%$ of its previous week connections to other nodes of the ego network the week after the shock, New York 38\%, and New Orleans $63 \%$. These connections are not retrieved within a period of two months: the resilience seems to take longer than for nodes. Yet on the five-month scale, the previous number of connections are retrieved and even may exceed the previous levels, in the case of New Orleans.

\section{[Table 1]}

Other indicators also exhibit common trends. The average shortest path length slightly decreases in the week after the shock. This means that the network lost efficiency due to the disruption of one of the region's major hub or gateway. Another similarity is the increase of Theta, which increases in the week after the shock before decreasing subsequently in all three cases. The lowering of average eccentricity confirms the loss of efficiency as ports get (topologically) further away from each other, as observed by Ducruet (2016) when removing canal-related circulations. Finally, all three disruptions converge by the increase of the average clustering coefficient, since the network became sparser after the shock, as the main gateway or hub was under threat. Other calculated indices tend to diverge and therefore are not further examined in this paper for the sake of space, but further research is needed to investigate the particularities of individual cases.

\section{Conclusion}

This research assessed the impacts of sudden and local exogenous shocks on selected ports. These shocks were studied on various temporal scales, from daily to yearly, and spatial scales, from the affected ports to their belonged region and maritime network. In all three case-studies, unpredicted events caused a temporary fall in the vessel traffic, due to infrastructure damage or security concerns. The time-scale of each shock differs depending on the type of traffic (container, bulk, passenger, or general cargo), as container flows are more sensitive to shocks. Containers is less vulnerable as it relies on widely available infrastructure and relies for a noticeable part on footloose transshipment. Dry and liquid bulk traffics reacted in an opposite manner, being more hinterlandoriented or market-sensitive in terms of seasonality (agriculture, commodities) and equipment (specialization).

It also demonstrated that shocks have all but random effects on regional port systems. Rerouting took place in the three case studies according to two crucial dimensions, topology and geography. In terms of spatial distance or geography, closer ports suffer durably ( $750 \mathrm{~km}$ radius) while faraway 
ports (800-1450 km radius) thrive in the weeks following the shock's occurrence. Topologically closer neighbors either lose connections and links in the case of dependence upon the affected ports, or improve their own connectivity when acting as replacement hubs and replacing the affected port. Although these disruptions are clearly visible from a bottom-up, comparative perspective, they do not endanger the global trade and maritime circulation pattern. In fact, the regional structure of maritime networks prevents the spread of local shocks to the global through shifts and interlinkages. At the opposite side of the coin, highly standardized, global maritime flows are handled and driven in such a hierarchical manner that ensuring global trade robustness turns out to increase the vulnerability of individual ports.

Further research about the impact of these disruptions is seen as multifold. Analyses on the longer term would benefit from a closer confrontation of our empirical results with those obtained from modelling, using theoretical models of network evolution and disruption, and from qualitative methods, using surveys and interviews towards local agents and policy makers. This would help to determine which part of port growth or collapse is due to disruptions, in the case of Busan but also Shanghai and Qingdao (China) after Kobe's failure for instance, and to understand shifts from one port to another. Taking into account the costs of such maritime shocks would also benefit the research, leaning towards spatial economics that have invested the field of transport studies for several decades now (Tavasszy et al., 2011). Cost assessment of the shocks, on both the short and the long term, would benefit a more precise approach on the opposition between efficiency and robustness. As disruptions of maritime networks lead to extra costs, there is a strong incentive for agents to reduce the occurrence of such events, as the system's vulnerability can be underestimated.

Other events could be compared as mentioned earlier, such as wars (civil or global, national or world war), economic crises (e.g. 1929, 2009, Asian crisis 1997-1998), dockworkers strikes, other natural disasters, and technological change like canal creation or closure (Suez, Panama) but also transitions in the shipping world like propulsion technology (see Bunel et al., 2017 for the case of sail to steam). Other metrics than vessel traffic could be integrated, such as vessel turnaround time (intra-port), vessel voyage duration and connectivity distance (inter-port) to verify ports' ability to reinsert international trade after the shock, and intermodal centrality measures such as land-sea (Berli et al., 2018). Although comparing three shocks caused by different types of events, occurring in different years, and in different ports was fruitful from a quantitative and network perspective, another possibility is to compare different shocks affecting the same port at different times in history, or to compare shocks occurring during the same year for different ports. Further research could go further by modeling the base network as if the shock did not occur, and compare it with the total network and the ego-network of the affected node.

\section{References}

Achurra-Gonzalez P., Angeloudis P., Zavitsas K., Niknejad A., Graham D.J. (2017) Attacker-defender modelling of vulnerability in maritime logistics corridors. In: Ducruet C. (Ed.), Advances in Shipping Data Analysis and Modeling. Tracking and Mapping Maritime Flows in the Age of Big Data. London and New York: Routledge, pp.

Amdal J., Swigart S. (2010) Resilient Transportation Systems in a Post-Disaster Environment: A Case Study of Opportunities Realized and Missed in the Greater New Orleans Region, Working Paper. 
Arvis J.F., Vesin V., Carruthers R., Ducruet C., De Langen P.W. (2019) Maritime Networks, Port Efficiency, and Hinterland Connectivity in the Mediterranean. World Bank Group, International Development in Focus, https://openknowledge.worldbank.org/handle/10986/30585

Asadabadi A., Miller-Hooks E. (2018) Co-opetition in enhancing global port network resiliency: A multi-leader, common-follower game theoretic approach. Transportation Research Part B, 108: 281298.

Bamberger, R.L., Kumins, L., n.d. Oil and Gas: Supply Issues After Katrina and Rita.

Banomyong R. (2005) The impact of port and trade security initiatives on maritime supply-chain management. Maritime Policy and Management, 32(1): 3-13.

Barthelemy M. (2015) Spatial networks: tools and perspectives. In: Ducruet C. (Ed.), Maritime Networks: Spatial Structures and Time Dynamics. London and New York: Routledge, pp. 50-60.

Berle $\varnothing$., Jr, J.B.R., Asbjørnslett B.E. (2011) Failure modes in the maritime transportation system: a functional approach to throughput vulnerability. Maritime Policy and Management, 38: 605-632.

Berli J., Bunel, M., Ducruet C. (2018) Sea-land interdependence in the global maritime network: The case of Australian port cities. Networks and Spatial Economics, 18(3): 467-471.

Bernhofen D.M., El-Sahli Z., Kneller R. (2016) Estimating the effects of the container revolution on world trade. Journal of International Economics, 98: 36-50.

Bradbury S.L. (2010) An assessment of the free and secure trade (FAST) program along the CanadaUS border. Transport Policy, 17: 367-380.

Bunel M., Bahoken F., Ducruet C., Lagesse C., Marnot B., Mermet E., Petit S. (2017) Geovisualizing the sail-to-steam transition through vessel movement data. In: Ducruet C. (Ed.), Advances in Shipping Data Analysis and Modeling. Tracking and Mapping Maritime Flows in the Age of Big Data. London and New York: Routledge, pp. 189-205.

Burden, L.I., Rix, G., Werner, S., 2016. Development of a risk framework for forecasting earthquake losses in port systems. Earthq. Spectra 32, 267-284.

Callaway D.S., Newman M.E.J., Strogatz S.H., Watts D.J. (2000) Network robustness and fragility: Percolation on random graphs. Physics Review Letters, 85: 5468-5471.

Cao X., Lam J.S.L. (2018) Simulation-based catastrophe-induced port loss estimation. Reliability Engineering and System Safety, 175: 1-12.

Caschili S., Reggiani A., Medda F. (2015) Resilience and vulnerability of spatial economic networks. Networks and Spatial Economics, 15(2): 205-210.

Chang, S.E., 2000. Disasters and transport systems: loss, recovery and competition at the Port of Kobe after the 1995 earthquake. J. Transp. Geogr. 8, 53-65.

Chang, S.E., 2003. Transportation Planning for Disasters: An Accessibility Approach. Environ. Plan. A 35, 1051-1072.

Chang, S.E., Nojima, N., 2001. Measuring post-disaster transportation system performance: the 1995 Kobe earthquake in comparative perspective. Transp. Res. Part Policy Pract. 35.

Chen, L., Miller-Hooks, E., 2012. Resilience: An Indicator of Recovery Capability in Intermodal Freight Transport. Transp. Sci. 46, 109-123. 
Chernick, H. (2005) Resilient City: The Economic Impact of 9/11. Russell Sage Foundation.

Cieslak, V., 2005. Ports in Louisiana: New Orleans, South Louisiana, and Baton Rouge (CRS Report for Congress).

City of Kobe, 2014. The Great Hanshin-Awaji Earthquake: Statistics and Restoration Progress. City of Kobe.

Cook Z., Franks D.W., Robinson E.J.H. (2014) Efficiency and robustness of ant colony transportation networks. Behavioral Ecology and Sociobiology, 68: 509-517.

Cowen, D., Bunce, S., 2006. Competitive Cities and Secure Nations: Conflict and Convergence in Urban Waterfront Agendas after 9/11. Int. J. Urban Reg. Res. 30, 427-439.

Cutter, S.L., Richardson, D.B., Wilbanks, T.J., 2014. The Geographical Dimensions of Terrorism. Routledge.

Daganzo, C.F., 2010. Structure of competitive transit networks. Transp. Res. Part B Methodol. 44, 434-446.

De Monie G., Rodrigue J.P., Notteboom T.E. (2011) Economic cycles in maritime shipping and ports: The path to the crisis of 2008. In: Hall P.V., McCalla R.J., Comtois C., Slack B. (Eds.), Integrating Seaports and Trade Corridors. Surrey: Ashgate, pp. 13-30.

Dekker A.H., Colbert B.D. (2004) Network robustness and graph topology. ACSC '04 Proceedings of the 27th Australasian Conference on Computer Science, Dunedin, New Zealand, 26: 359-368.

Deng W.B., Long G., Wei L., Xu C. (2009) Worldwide marine transportation network: Efficiency and container throughput. Chinese Physics Letters, 26(11): 118901.

Derrible, S., Kennedy, C., 2010. The complexity and robustness of metro networks. Phys. Stat. Mech. Its Appl. 389, 3678-3691.

Dillon, R.L., Mazzola, J.B., 2010. Management of disruption risk in global supply chains. IBM J. Res. Dev. 54, 10:1-10:9.

Dolfman, M.L., Fortier, S., 2007. The effects of Hurricane Katrina on the New Orleans economy. Mon. Labor Rev. 16.

Dou B.L., Wang X.G., Zhang S.Y. (2010) Robustness of networks against cascading failures. Physica A, 389: 2310-2317.

Ducruet C. (2008) Hub dependence in constrained economies: The case of North Korea. Maritime Policy and Management, 35(4): 374-388.

Ducruet C. (2016) The polarization of global container flows by interoceanic canals: Geographic coverage and network vulnerability. Maritime Policy and Management, 43(2): 242-260.

Ducruet C., Beauguitte L. (2014) Network science and spatial science: Review and outcomes of a complex relationship. Networks and Spatial Economics, 14(3-4): 297-316.

Ducruet C., Lee S.W., Roussin S. (2017) Geopolitical and logistical factors in the evolution of North Korea's shipping flows. In: Ducruet C. (Ed.), Advances in Shipping Data Analysis and Modeling. Tracking and Mapping Maritime Flows in the Age of Big Data. London and New York: Routledge, pp. 357-379. 
Ducruet C., Lugo I. (2013) Structure and dynamics of transportation networks: Models, concepts, and applications. In: Rodrigue J.P., Notteboom T.E., Shaw J. (Eds.), The SAGE Handbook of Transport Studies, SAGE Publications, pp. 347-364.

Earnest, D.C., Yetiv, S., Carmel, S.M., 2012. Contagion in the Transpacific Shipping Network: International Networks and Vulnerability Interdependence. Int. Interact. 38, 571-596.

Edgington, D.W., 2011. Reconstructing Kobe: The Geography of Crisis and Opportunity. UBC Press, Vancouver.

Fang, Z., Yu, H., Lu, F., Feng, M., Huang, M., 2018. Maritime network dynamics before and after international events. J. Geogr. Sci. 28, 937-956.

Frémont A. (2015) A geo-history of maritime networks since 1945. The case of the Compagnie Générale Transatlantique's transformation into CMA-CGM, In: Ducruet C. (Ed.), Maritime Networks: Spatial Structures and Time Dynamics. London and New York: Routledge.

Frittelli, J., n.d. Hurricane Katrina: Shipping Disruptions.

Fu X., Ng A.K.Y., Lau J.J. (2010) The impacts of maritime piracy on global economic development: the case of Somalia. Maritime Policy and Management, 37(7): 677-697.

Gastner, M.T., Newman, M.E.J., 2006. The spatial structure of networks. Eur. Phys. J. B 49, 247-252.

Godoy Luis A., 2007. Performance of Storage Tanks in Oil Facilities Damaged by Hurricanes Katrina and Rita. J. Perform. Constr. Facil. 21, 441-449.

Gotham, K.F., Greenberg, M., 2014. Crisis Cities: Disaster and Redevelopment in New York and New Orleans. Oxford University Press.

Grenzeback, L.R., Lukmann, A.T., Systematics, C., 2008. Case Study of the Transportation Sector's Response to and Recovery from Hurricanes Katrina and Rita. Transp. Res. Board.

Guerrero, D., Rodrigue, J.-P., 2014. The waves of containerization: shifts in global maritime transportation. J. Transp. Geogr. 34, 151-164.

Guinand, F., Pigné, Y., 2015. Time considerations for the study of complex maritime networks, in: Maritime Networks: Spatial Structures and Time Dynamics. Routledge.

Gurning, S., Cahoon, S., Dragovic, B., Nguyen, H.-O., 2013. Modelling of Multi-Mitigation Strategies for Maritime Disruptions in the Wheat Supply Chain. Journal Mech. Eng. 9, 499-510.

Hall, P.V., 2004. "We'd Have to Sink the Ships": Impact Studies and the 2002 West Coast Port Lockout. Econ. Dev. Q. 18, 354-367.

Hayashi, Y., Matsukubo, J., 2006. Geographical effects on the path length and the robustness in complex networks. Phys. Rev. E 73, 066113.

Hayuth Y. (1981) Containerization and the load center concept. Economic Geography, 57(2): 160-176.

Høye, G.K., Eriksen, T., Meland, B.J., Narheim, B.T., 2008. Space-based AIS for global maritime traffic monitoring. Acta Astronaut. 62, 240-245.

Hu, Y., Zhu, D., 2009. Empirical analysis of the worldwide maritime transportation network. Phys.

Stat. Mech. Its Appl. 388, 2061-2071. 
Irwin, K.L.A. and N., 2005. Port Comes Back Early, Surprisingly.

Jacobs W., Notteboom T.E. (2011) An evolutionary perspective on regional port systems: the role of windows of opportunity in shaping seaport competition. Environment and Planning A, 43(7): 16741692.

Kates, R.W., Colten, C.E., Laska, S., Leatherman, S.P., 2006. Reconstruction of New Orleans after Hurricane Katrina: A research perspective. Proc. Natl. Acad. Sci. 103, 14653-14660.

Kireyev A., Leonidov A. (2018) Network effects of international shocks and spillovers. Networks and Spatial Economics, 18(4): 805-836.

Kunishima, M., Abe, M., n.d. The Hanshin Awaji Great Earthquake. Failure Knowledge Database: http://www.sozogaku.com/fkd/en/

Leavitt, W.M., Kiefer, J.J., 2006. Infrastructure Interdependency and the Creation of a Normal Disaster: The Case of Hurricane Katrina and the City of New Orleans. Public Works Manag. Policy 10, 306-314.

Lee H., Boile M., Theofanis S., Choo S. (2012) Modeling the oligopolistic and competitive behavior of carriers in maritime freight transportation networks. Procedia - Social and Behavioral Sciences, 54: 1080-1094.

Lee S.W., Ducruet C. (2009) Spatial glocalization in Asia-Pacific hub port cities: A comparison of Hong Kong and Singapore. Urban Geography, 30(2): 162-184.

Lemarchand A., Joly O. (2009) Regional integration and maritime range. In: Notteboom T.E., Ducruet C., De Langen P.W. (Eds.), Ports in Proximity: Competition and Coordination among Adjacent Seaports, Aldershot: Ashgate, pp. 87-99.

Lhomme S. (2015) Vulnerability and resilience of ports and maritime networks to cascading failures and targeted attacks. In: Ducruet C. (Ed.), Maritime Networks. Spatial Structures and Time Dynamics. London and New York: Routledge, pp. 229-240.

Li J., Ozbey K. (2015) Evacuation planning with endogenous transportation network degradations: A stochastic cell-based model and solution procedure. Networks and Spatial Economics, 15(3): 677696.

Liu, C., Wang, J., Zhang, H., 2018. Spatial heterogeneity of ports in the global maritime network detected by weighted ego network analysis. Marit. Policy Manag. 45, 89-104.

Loh, H.S., Van Thai, V., 2014. Managing Port-Related Supply Chain Disruptions: A Conceptual Paper. Asian J. Shipp. Logist. 30, 97-116.

Lordan, O., Sallan, J.M., Escorihuela, N., Gonzalez-Prieto, D., 2016. Robustness of airline route networks. Phys. Stat. Mech. Its Appl. 445, 18-26.

MacPherson, A.D., McConnell, J.E., Vance, A., Vanchan, V., 2006. The Impact of U.S. Government Antiterrorism Policies on Canada-U.S. Cross-Border Commerce: An Exploratory Study from Western New York and Southern Ontario. Prof. Geogr. 58, 266-277.

Mareï N., Ducruet C. (2015) The regionalization of maritime networks: Evidence from a comparative analysis of maritime basins. In: Ducruet C. (Ed.), Maritime Networks: Spatial Structures and Time Dynamics. London and New York: Routledge, pp. 330-350. 
Marston S.A., Jones J.P., Woodward K. (2005) Human geography without scale. Transactions of the Institute of British Geographers, 30: 416-432.

Michels, S., Velikova, M., Hommersom, A., Lucas, P.J.F., 2013. A Decision Support Model for Uncertainty Reasoning in Safety and Security Tasks, in: 2013 IEEE International Conference on Systems, Man, and Cybernetics. Presented at the 2013 IEEE International Conference on Systems, Man, and Cybernetics, pp. 663-668.

Mullai, A., Paulsson, U., 2011. A grounded theory model for analysis of marine accidents. Accid. Anal. Prev. 43, 1590-1603.

Nagurney, A., Qiang, Q., 2007. Robustness of transportation networks subject to degradable links. Europhys. Lett. EPL 80, 68001.

Notteboom, T.E., Ducruet, C., Langen de, P.W. (2009) Ports in Proximity: Competition and Cooperation among Adjacent Seaports. Aldershot: Ashgate.

O’Kelly, M.E., 2015. Network Hub Structure and Resilience. Netw. Spat. Econ. 15, 235-251.

Okuyama, Y., 2015. The Rise and Fall of the Kobe Economy from the 1995 Earthquake. J. Disaster Res. $10,635-640$.

Oliva, S., Lazzeretti, L., 2017. Adaptation, adaptability and resilience: the recovery of Kobe after the Great Hanshin Earthquake of 1995. Eur. Plan. Stud. 25, 67-87.

Omer, M., Mostashari, A., Nilchiani, R., Mansouri, M., 2012. A framework for assessing resiliency of maritime transportation systems. Marit. Policy Manag. 39, 685-703.

Paul, J.A., Maloni, M.J., 2010. Modeling the effects of port disasters. Marit. Econ. Logist. 12, 127-146.

Pettit S., Beresford A. (2018) Port Management: Cases in Port Geography, Operations and Policy. London and New York: Kogan Page.

Qi, X., 2015. Disruption management for liner shipping. Int. Ser. Oper. Res. Manag. Sci. 220, 231-249. Reuters, 2005. Rita and Katrina Have Shut 23 Percent of U.S. Oil Refining Capacity. N. Y. Times. Richardson, M., 2004. A Time Bomb for Global Trade: Maritime-related Terrorism in an Age of Weapons of Mass Destruction. Institute of Southeast Asian Studies.

Robinson, R., 1968. Spatial structuring of port-linked flows; The Port of Vancouver, Canada, 1965. University of British Columbia.

Robinson, R., 2002. Ports as elements in value-driven chain systems: the new paradigm. Marit. Policy Manag. 29, 241-255.

Rodrigue J.P., Comtois C., Slack B. (2013) The Geography of Transport Systems, London and New York: Routledge.

Rodrigue J.P., Notteboom T.E. (2010) Foreland-based regionalization: Integrating intermediate hubs with port hinterlands. Research in Transportation Economics, 27(1): 19-29.

Rodrigue, J.-P., 2004. Appropriate models of port governance. Lessons from the Port Authority of New York and New Jersey, in: Shipping and Ports in the Twenty-First Century: Globalisation, Technological Change and the Environment. 
Rose, A., Wei, D., 2013. Estimating the Economic Consequences of a Port Shutdown: The Special Role of Resilience. Econ. Syst. Res. 25, 212-232.

Rose, R., Bradley, D., Conley, J., Garlock, T., 2010. Doing Business across the Canada-United States Border: Gateway or Checkpoint. Can.-U. S. Law J. 34, 35.

Rosoff, H., von Winterfeldt, D., 2007. A risk and economic analysis of dirty bomb attacks on the ports of Los Angeles and Long Beach. Risk Anal. Off. Publ. Soc. Risk Anal. 27, 533-546.

Scott, D.M., Novak, D.C., Aultman-Hall, L., Guo, F., 2006. Network Robustness Index: A new method for identifying critical links and evaluating the performance of transportation networks. J. Transp. Geogr. 14, 215-227.

Shafieezadeh, A., Ivey Burden, L., 2014. Scenario-based resilience assessment framework for critical infrastructure systems: Case study for seismic resilience of seaports. Reliab. Eng. Syst. Saf. 132, 207219.

Shaw, D.R., Grainger, A., Achuthan, K., 2017. Multi-level port resilience planning in the UK: How can information sharing be made easier? Technol. Forecast. Soc. Change 121, 126-138.

Skipper, J.B., Hanna, J.B., Gibson, B.J., n.d. Applying contingency planning processes to supply chain disruptions: a service provider's response to hurricane Katrina 15.

Slack, B., 1993. Pawns in the Game: Ports in a Global Transportation System. Growth Change 24, 579588.

Slack B., Wang J.J. (2002) The challenge of peripheral ports: an Asian perspective. Geojournal, 56(2): 159-166.

Song, D., Zhang, J., Carter, J., Field, T., Marshall, J., Polak, J., Schumacher, K., Sinha-Ray, P., Woods, J., 2005. On cost-efficiency of the global container shipping network. Marit. Policy Manag. 32, 15-30.

Sorkin, M., Zukin, S. (Eds.), 2002. After the World Trade Center: Rethinking New York City, 1 edition. ed. Routledge, New York.

Tavasszy L.A., Minderhoud M., Perrin J.F., Notteboom T.E. (2011) A strategic network choice model for global container flows: Specification estimation and application. Journal of Transport Geography, 19(6): 1163-1172.

Thai, V.V., 2009. Effective maritime security: conceptual model and empirical evidence. Marit. Policy Manag. 36, 147-163.

Vigarié A. (1995) La Mer et la Géostratégie des Nations. Paris: Economica.

Vigdor, J., 2008. The Economic Aftermath of Hurricane Katrina. J. Econ. Perspect. 22, 135-154.

Viljoen N.M., Joubert J.W. (2016) The vulnerability of the global container shipping network to targeted link disruption. Physica A, 462: 396-409.

Wachtendorf, T., Brown, B., Holguin-Veras, J., 2013. Catastrophe Characteristics and their Impact on Critical Supply Chains: Problematizing Materiel Convergence and Management Following Hurricane Katrina. J. Homel. Secur. Emerg. Manag. 10, 497-520.

Walker, A.R., 1989. Recessional and Gulf War Impacts on Port Development and Shipping in the Gulf States in the 1980's. GeoJournal 18, 273-284. 
Wang C., Ducruet C. (2013) Regional resilience and spatial cycles: Long-term evolution of the Chinese port system (221BC-2010AD). Tijdschrift voor Economische en Sociale Geografie, 104(5): 521-538.

Wang J.W., Rong L.L. (2011) Robustness of the Western United States power grid under edge attack strategies due to cascading failures. Safety Science, 49: 807-812.

Wei, T., Guishi, D., Peijian, W., Wenjiao, C. (2007) Analysis of complexity in global shipping network. Dalian Ligong Daxue Xuebao 47, 605-609.

Wu, T., Blackhurst, J., O'grady, P. (2007) Methodology for supply chain disruption analysis. Int. J. Prod. Res. 45, 1665-1682.

Xu H., Itoh H. (2018) Density economies and transport geography: Evidence from the container shipping industry. Journal of Urban Economics, 105: 121-132.

Zreik R., Ducruet C., Bouveyron C., Latouche P. (2017) Cluster dynamics in the collapsing Soviet shipping network. In: Ducruet C. (Ed.), Advances in Shipping Data Analysis and Modeling. Tracking and Mapping Maritime Flows in the Age of Big Data, London and New York: Routledge, pp. 317-337. 


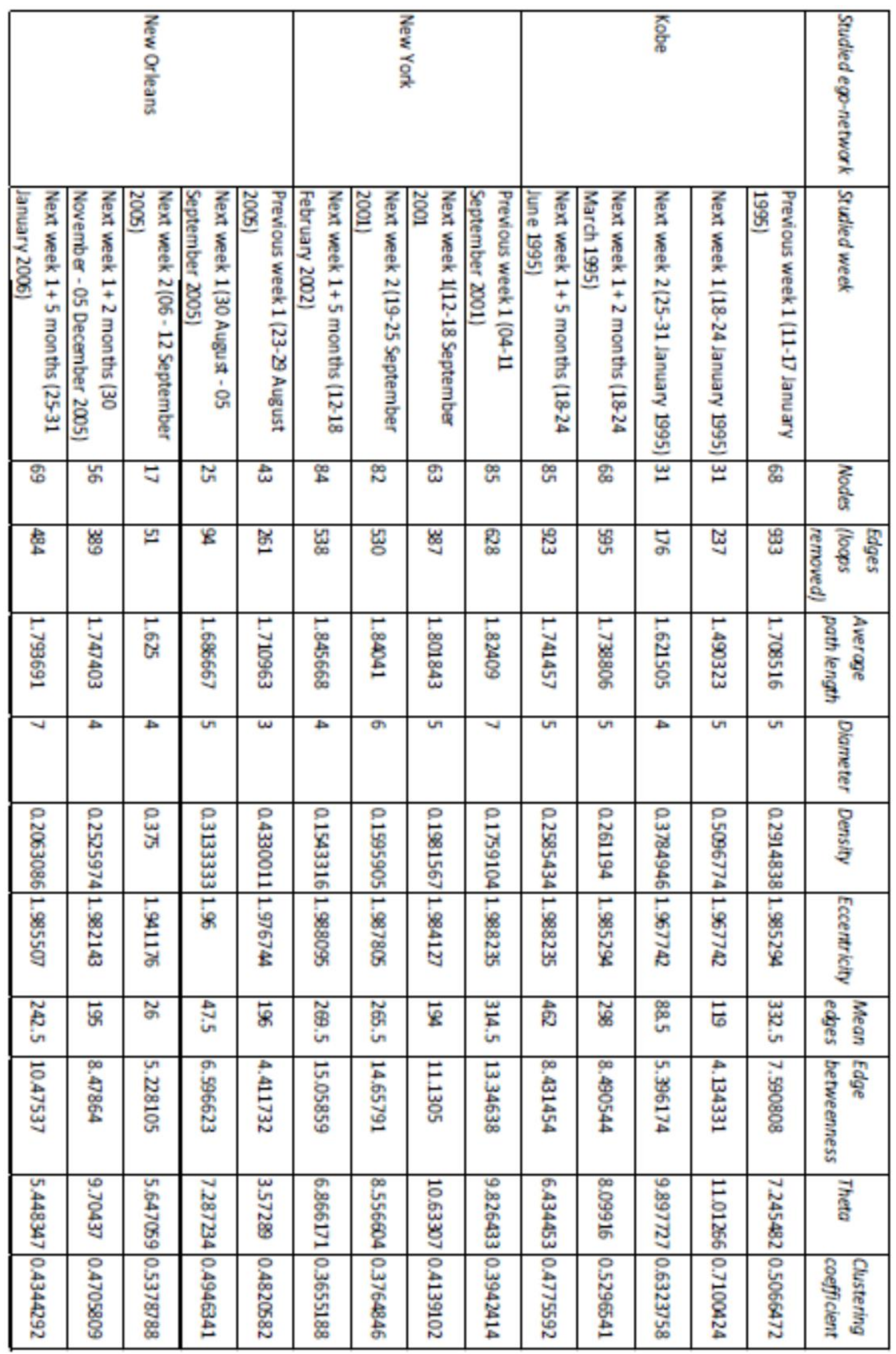

Table 1: Changing structure of studied maritime ego-networks

Source: own realization based on Lloyd's List Intelligence data 


\begin{tabular}{|l|l|l|}
\hline Scale & \multicolumn{1}{|c|}{ Index } & \multicolumn{1}{c|}{ Definition } \\
\hline \multirow{4}{*}{$\begin{array}{c}\text { Global (ego- } \\
\text { network) }\end{array}$} & No. nodes (vertices) & - \\
\cline { 2 - 3 } & No. links (edges) & - \\
\cline { 2 - 3 } & Average shortest path length & Average length of all shortest paths (efficiency) \\
\cline { 2 - 3 } & Diameter & Maximum length of all shortest paths \\
\cline { 2 - 3 } & Aensity (Gamma) & Share of actual links in the complete network \\
\cline { 2 - 3 } & Average eccentricity & Average no. of stops between all port pairs \\
\cline { 2 - 3 } & Theta & Average no. of shortest paths on all port pairs \\
\cline { 2 - 3 } & Average clustering coefficient & Average traffic per node \\
\hline & Clustering coefficient & Meshedness of the network between 0 and 1 \\
\cline { 2 - 3 } & Eccentricity & Probability for a node's neighbors to connect \\
\cline { 2 - 3 } & Betweenness centrality & Topological proximity other network nodes \\
\cline { 2 - 3 } & Weighted degree centrality & Total vessel traffic (DWT) \\
\cline { 2 - 3 } & Weighted in-degree & Total inbound vessel traffic (DWT) \\
\cline { 2 - 3 } & Weighted out-degree & Total outbound vessel traffic (DWT) \\
\cline { 2 - 3 } & Degree centrality & Number of directly connected neighbor nodes \\
\cline { 2 - 3 } & In-degree & Number of inbound links from other nodes \\
\cline { 2 - 3 } & Out-degree & Number of outbound links to other nodes \\
\hline
\end{tabular}

\section{Appendix 2: List and definition of selected network indices}

Source: own realization based on Ducruet and Rodrigue (2018) 


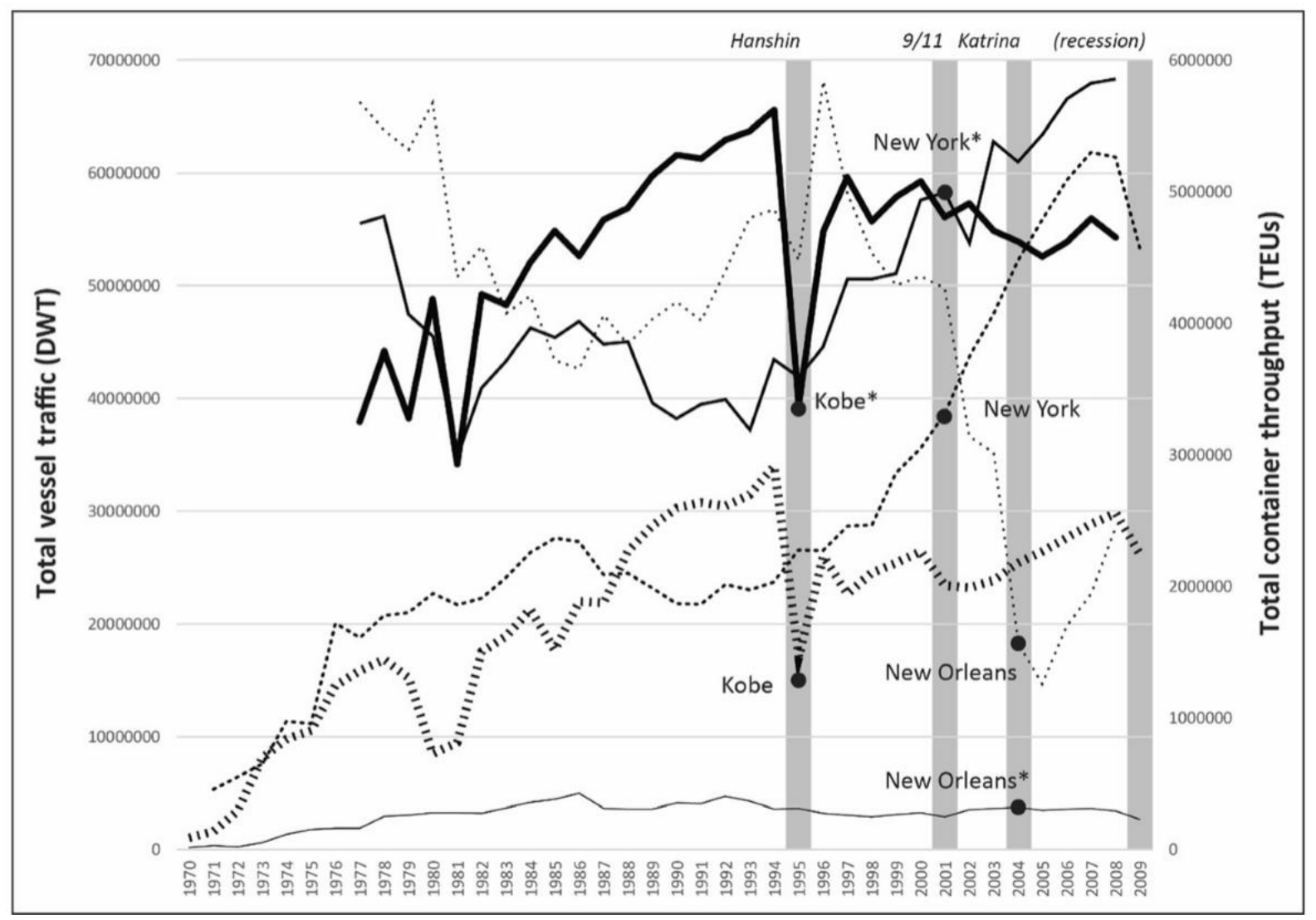

Figure 1: Yearly port throughput and vessel traffic by case study, 1970-2009

Source: own realization based on Lloyd's List Intelligence data and Containerisation International 


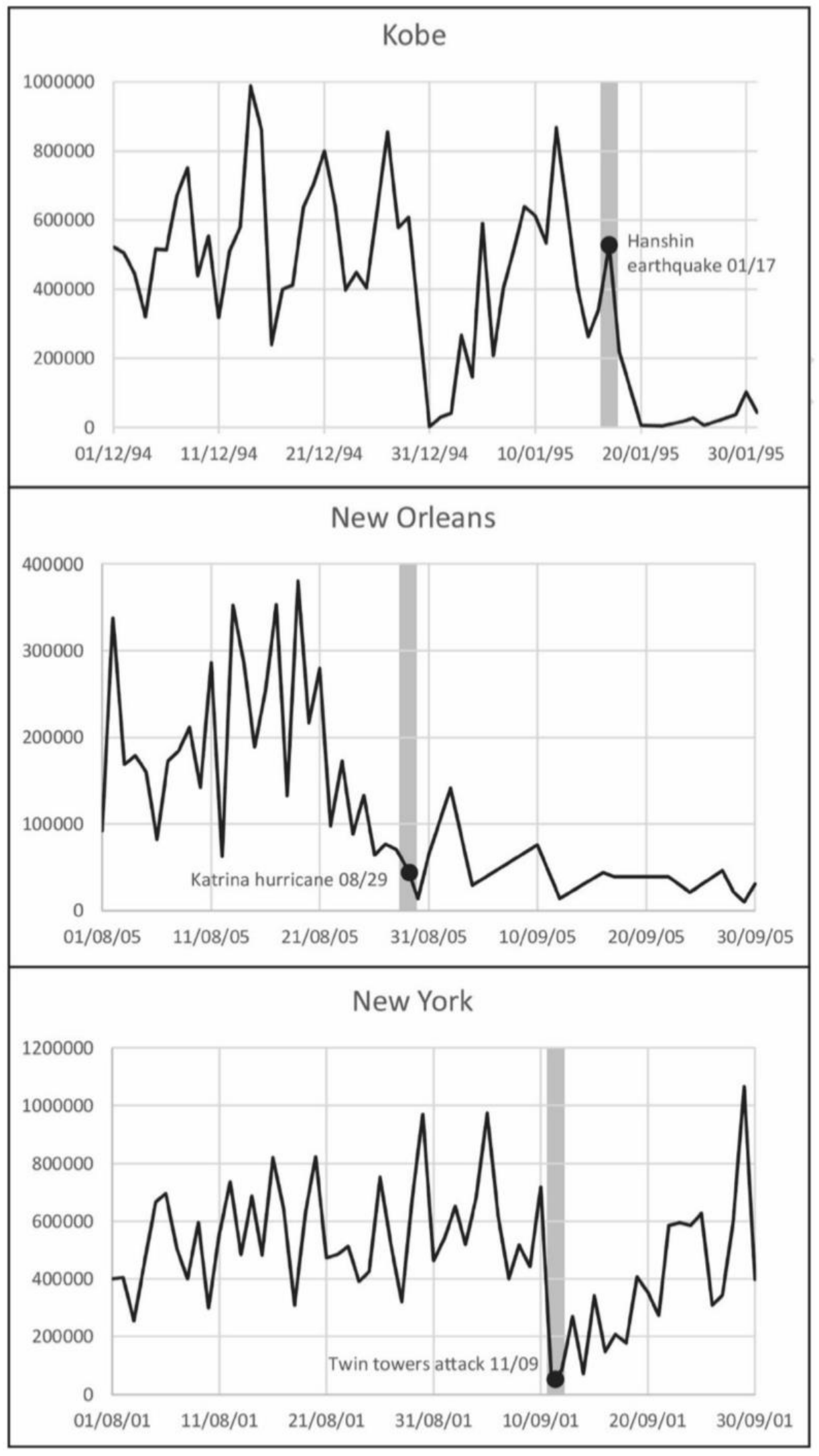

Figure 2: Daily vessel traffic at selected ports (Unit: DWT)

Source: own realization based on Lloyd's List Intelligence data 


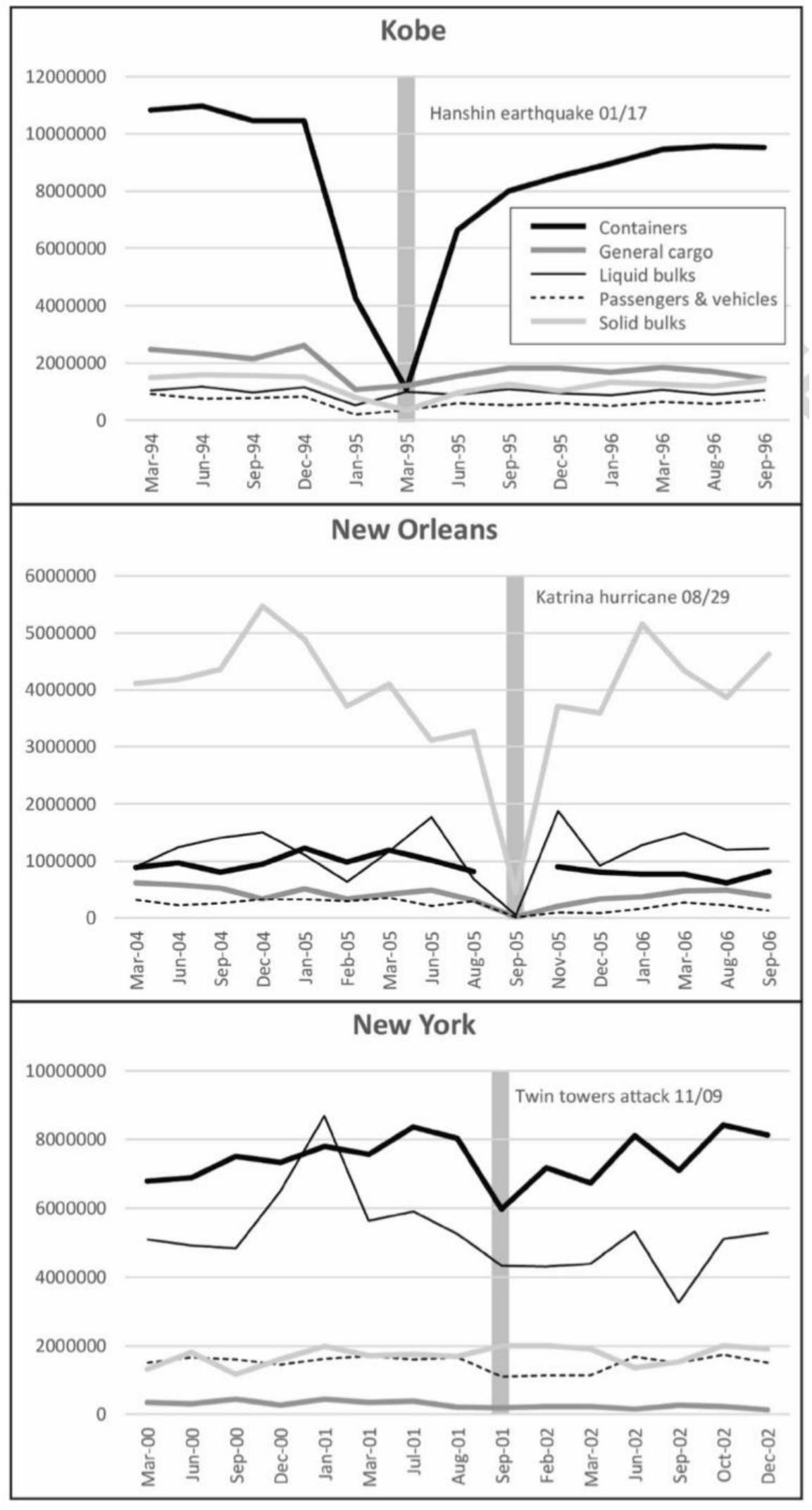

Figure 3: Monthly vessel traffic at selected ports by main traffic type (Unit: DWT)

Source: own realization based on Lloyd's List Intelligence data 


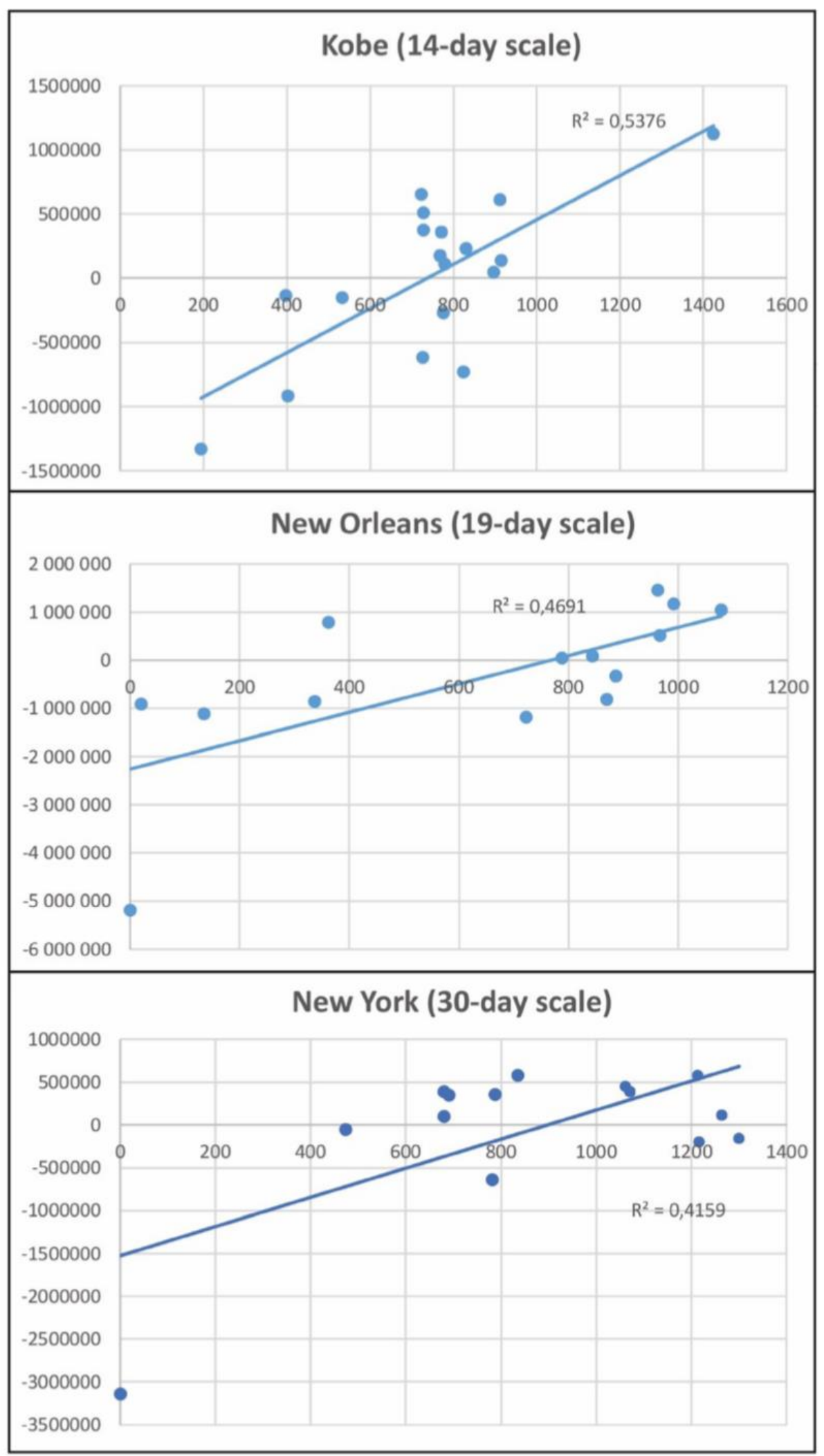

Figure 4: Traffic change vs. geographic distance within regional port systems Source: own realization based on Lloyd's List Intelligence data

N.B. distance in nautical miles (NM) and traffic in deadweight tons (DWT) 

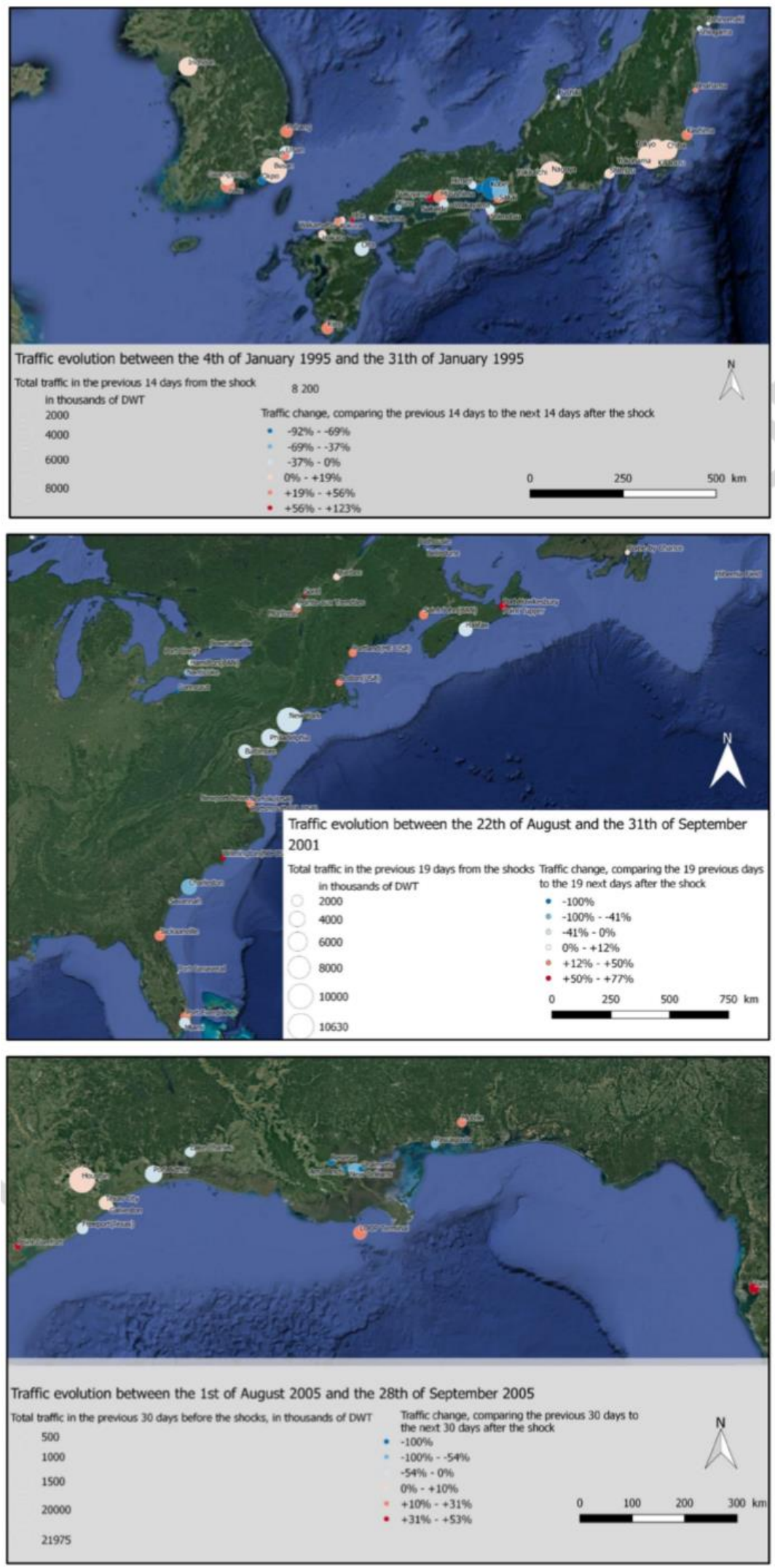

Figure 5: Traffic change vs. geographic distance at disrupted ports and their neighbors

Source: own realization based on Lloyd's List Intelligence data 


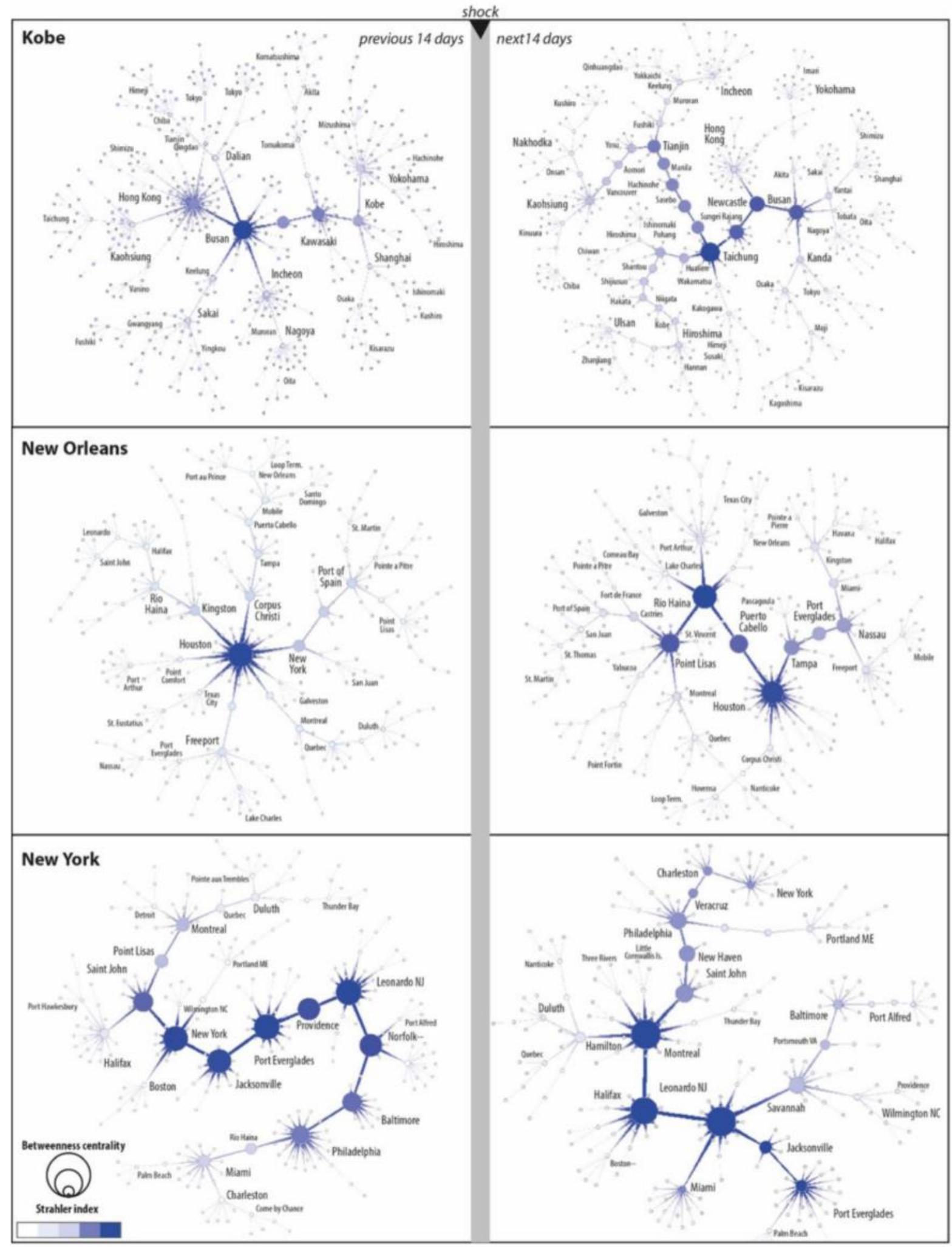

Figure 6: Network pattern per selected port before and after disruption

Source: own realization based on Lloyd's List Intelligence data and TULIP software 